\title{
The implications of sex role identity and psychological capital for organisations: A South African study

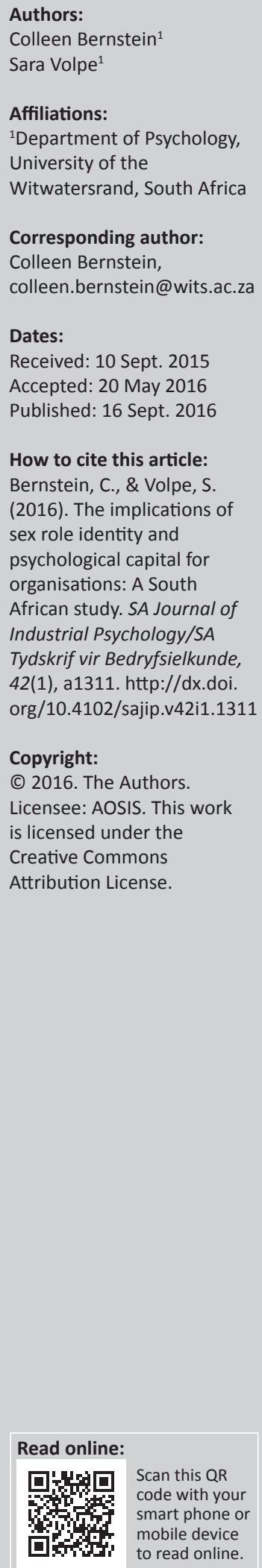

Orientation: A large body of research evidence indicates that both sex role identity (SRI) and psychological capital (PsyCap) may have critical implications for individual and organisational well-being. As SRI is constituted of sex-based personality traits it is possible that SRI may have implications for individuals' PsyCap.

Research purpose: The purpose of this study was to investigate the relationship between SRI and the positive psychological construct of PsyCap.

Motivation for the study: Research on SRI and PsyCap has been explored independently of one another with a lack of research exploring the relationship between these two constructs. In addition, much of the previous research on SRI and organisational outcomes has only examined positive sex role identities, focusing almost exclusively on 'positive' or 'socially desirable' sex role identities. More recently, researchers have noted that this approach is theoretically and methodologically flawed, as it fails to account for negative traits or socially undesirable traits that may be contained within individuals' SRI and which may have a number of deleterious implications for organisational outcome variables. Furthermore, there is a paucity of research within the South African context, which explores the adoption of positive and negative sexbased behavioural traits and their implications for PsyCap.

Research design, approach and method: A quantitative study was conducted using a crosssectional design and a convenience sampling method to explore the relationship between SRI and PsyCap. Four hundred and seventy-eight respondents, all currently working in South African organisations, participated in this research. The composite questionnaire utilised for this research included a demographic questionnaire, The Extended Personal Attribute Questionnaire-Revised (EPAQ-R), and the PCQ-24 which measures PsyCap in terms of selfefficacy, hope, resilience and optimism.

Main findings: Statistically significant differences were found between the positive and negative SRIs for levels of PsyCap. In particular, positive androgyny and positive masculinity scored the highest levels of PsyCap, whereas negative androgyny and negative femininity consistently scored the lowest levels. Although positive femininity fared significantly better than the aforementioned negative identities in most instances, this identity scored significantly lower levels on the positive PsyCap outcomes of hope and resilience, than the other positive identities of positive androgyny and positive masculinity. Furthermore, and counterintuitively, within this South African study, negative masculinity fared unexpectedly better on all dimensions of PsyCap, as compared to the poorer outcomes for negative masculinity evidenced in other international research.

Practical/managerial implications: Given the pervasive impact of SRIs and PsyCap on interpersonal and organisational functioning, this research has practical and managerial implications for organisations with regard to recruitment, selection, training and development, and workplace counselling interventions.

Contribution/value-add: The findings of this research contribute to the paucity of literature investigating both positive and negative SRIs and contribute further by exploring the interrelationship between these identities and PsyCap. As this study utilised a sample of individuals working in South Africa, its findings have a direct bearing on South African organisations.

\section{Introduction}

A large body of research has been conducted which investigates the relationship between sex role identities (SRIs) of androgyny, masculinity, femininity and a number of critical organisational outcomes. In this regard it has been reported that those who are more androgynous or masculine 
have significantly more flexible coping styles, and are higher on self-esteem, achievement motivation, subjective feelings of well-being, resilience, improved self-concept, improved work performance and work engagement. Androgyny has also been significantly correlated with greater creativity and emotional intelligence (Cheng, 1999; Flaherty \& Dusek, 1980; Guastello \& Guastello, 2003; Jacobs, 2014; Jurma \& Powell, 1994; Keller, Lavish \& Brown, 2007; Lam \& McBride-Chang, 2007; Lassk, Kennedy, Powell \& Lagace, 1992; May \& Spangenberg, 1997). Those that are feminine or androgynous are found to have a greater ability to harness and utilise social support and are more embedded in strong networks of supportive others, both in their personal lives and within the workplace (Bernstein, 2013; Bornstein et al., 2002; Kitamura et al., 2002; Neff \& Karney, 2005; Reevy \& Maslach, 2001). Within this approach masculinity has typically included traits of assertiveness, decision-making ability, control, competitiveness, ambition, independence, self-sufficiency and goal-orientation (Bem, 1974; Spence, Helmreich \& Holohan, 1979). Femininity has included traits of being emotional, tactful, considerate, warm, gentle and caring (Spence, 1993; Spence et al., 1979) while androgyny has been defined as the possession of high levels of both masculinity and femininity (Woodhill \& Samuels, 2003, 2004).

A growing body of research has also demonstrated the critical relationship between psychological capital (PsyCap) and crucial organisational outcomes, indicating that PsyCap has a positive effect on important work attitudes and behaviours, such as job satisfaction, organisational commitment, absenteeism, turnover intentions, organisational citizenship behaviour and work performance (Avey, 2014; Avey, Luthans, Smith \& Palmer, 2010; Choi \& Lee, 2013; Schaufeli, Bakker \& Salanova, 2006). However, there is very little research that explores the interrelationship between constructs of SRI and PsyCap. Avey (2014) and Choi and Lee (2013) in fact suggest that personality may be an antecedent of PsyCap and, as SRI is constituted of sex-based personality traits, the present study undertook to determine if any association indeed exists between these two variables.

Furthermore, as all the aforementioned studies on SRI examined positive SRIs only, the present study undertook to examine the relationship between both positive and negative SRIs and PsyCap. This undertaking was driven by previous research findings on positive SRIs that have at times shown no relationship with health outcome variables or that there is even an inverse relationship with such variables. It has been argued that these inconsistent and at times counterintuitive findings may be due to the possibility that SRI consists of more than positive, socially desirable sex-based traits. Since the 1980s an ever-increasing subgroup of researchers on SRI have suggested that the construct consists of more dimensions than originally proposed and have argued for distinguishing or differentiating between socially desirable (positive) and undesirable (negative) gender role traits (Athenstaedt, 2003; Berger \& Krahe, 2013; Bernstein, 2013; McCreary \& Korabik, 1994; Ricciardelli \& Williams, 1995; Spence et al., 1979;
Wajsblat, 2011; Woodhill \& Samuels, 2003, 2004). These researchers note that in the event of negative attributes being present, and their contribution not being assessed, this could confound research findings. In this regard a differentiated model which enables the examination of both positive and negative gendered attributes has been proposed (Berger \& Krahe, 2013; Wajsblat, 2011; Woodhill \& Samuels, 2003, 2004), and it is this model which was used in the present study to explore the relationship between SRIs and PsyCap. Use of this model is further supported by a recent South African Research Project which examined the relationship between positive and negative SRIs across nine different studies. Within these studies the relationship between positive and negative SRIs and variables of emotional intelligence, job satisfaction, work engagement, self-esteem, general psychological well-being, work culture preferences, conflict resolution strategies, perceptions of academic and work stress, work-family conflict, and perceived work (colleague and supervisor) and family, friend and partner and/or significant other social support (Berman, 2013; Bernstein, 2013; Chemaly, 2012, 2013; DeFreitas, 2013, 2014; Kilgour, 2014; Solomon, 2012; Sugden, 2014) were examined.

To follow is a discussion of the literature on SRIs, PsyCap and the proposed interrelationships between positive and negative SRIs and PsyCap.

\section{Literature review}

\section{Sex role identity}

SRI refers to the sex-based personality traits that individuals have adopted into their behavioural repertoire. Although some theorists believe that the adoption of stereotypical gendered behaviour is innate (Gergen \& Davis, 1997; Johnson, Greaves \& Repta, 2007), since the 1970s, there has been a paradigmatic shift towards social constructionism which posits that an individual's adoption of traits and behaviours reflects social and cultural prescriptive and normative attitudes of 'appropriate' or sex-congruent traits and behaviours for each biological sex (Heilman, 2012; West \& Zimmerman, 1987).

Traditionally, prior to the work of Bem in the 1970s 'appropriate' sex-congruent traits were those that were 'prescribed' as socially acceptable for an individual's biological sex while non-congruent traits were those 'proscribed' and considered not to be socially acceptable as they were designated to the opposite sex. Thus, masculine SRI traits, such as competitiveness, toughness and assertiveness, were strictly prescribed for biological males and feminine SRI traits, such as gentleness, helpfulness, caring, warmth and nurturance, were strictly prescribed for biological females. However, with the enormous social changes that have occurred since the 1970s, more especially with the rise of feminism, theorists have challenged the adoption of traditional sex-congruent traits, acknowledging that an individual can display both stereotypically masculine and feminine traits, regardless of their biological sex. With 
the advent of Bem's work (1974) which brought about a sea change in the way in which gender was viewed, the concept of 'androgyny' was proposed. Androgyny proposed that an individual could adopt a 'balance' of both masculine and feminine traits, irrespective of their biological sex and that this combination was in fact the developmental ideal in that individuals who could combine both sets of traits within their behavioural repertoire would be able to adapt to a wider variety of situational demands (Borna \& White, 2003; Woodhill \& Samuels, 2004). Utilising this approach, measuring instruments were developed, the most commonly used being the Bem Sex Role Inventory (BSRI), which described four SRI behavioural clusters of socially desirable sex-based traits; namely masculine, feminine, androgynous and undifferentiated, the latter being a category used to describe individuals that score low on both masculine and feminine traits (Bem, 1974).

However, this research was restricted to the investigation of 'positive' socially desirable sex-based behavioural traits only failing to account for the possible existence and impact of an individual's negative or socially undesirable sex-based traits (Berger \& Krahe, 2013; Bernstein, 2013; Bernstein \& Osman, 2016; Wajsblat, 2011; Woodhill \& Samuels, 2003; 2004). Socially desirable SRIs included positive masculinity which consisted of traits such as assertiveness, decision-making ability, control, competitiveness, ambition, independence, self-sufficiency and goal-orientation (Bem, 1974; Helmreich, Spence \& Wilhelm, 1981) and positive femininity which consisted of traits such as being emotional, tactful, considerate, warm, gentle and caring (Spence et al., 1975). Positive androgyny was defined as the possession of high levels of both positive masculinity and positive femininity (Woodhill \& Samuels, 2003, 2004).

What this approach did not measure was socially undesirable sex-based traits, for example, negative masculinity which encompasses traits such as authoritarianism, aggression, dominance, arrogance and hostility (Helgeson \& Fritz, 2000) and negative femininity which includes traits such as timidity, passivity, anxiety, neuroticism, excessive worrying, complaining and submissiveness (Woodhill \& Samuels, 2003, 2004). Negative androgyny would thus incorporate high levels of both negative masculinity and negative femininity (Woodhill \& Samuels, 2003).

\section{Psychological capital}

Positive PsyCap, commonly referred to as PsyCap, is a synergistic higher order construct which aggregates the four underlying positive psychological capacities of self-efficacy, hope, resilience and optimism (Luthans \& Youssef, 2004; Luthans, Avolio, Avey \& Norman, 2007). Though conceptually distinct, these four capabilities or resources have strong commonalities and underlying links. Further, although the four PsyCap resources may remain stable over periods of time, they are not totally static and can be developed and enhanced through focused interventions and/or induced by environmental factors (Youssef \& Luthans, 2007). Self-efficacy refers to an individual's belief in their capability to take necessary action and sustain motivation to achieve an outcome (Bandura, 1977). Individuals with high self-efficacy are more likely to choose difficult tasks and persevere in the face of adversity, given that they are optimistic of achieving their outcomes, with such individuals typically outperforming those with low self-efficacy (Bandura, 1977). Hope is a positive motivational state comprised of two dimensions; agency and pathways (Snyder, 2000). Agency refers to the goal-directed motivation to pursue and achieve desired outcomes (Snyder, 2000). Pathways is the belief in one's ability to create plans to achieve a goal, and develop alternative plans when obstacles arise (Snyder, 2000). Resilience describes an individual's ability to cope in the face of significant adversity or change (Stewart, Reid \& Mangham, 1997). Resilience includes the ability to adapt to uncertainty and involves the recognition of the need to take proactive and reactive steps to overcome challenges (Youssef \& Luthans, 2007). Optimism reflects a generalised positive explanatory style, with an expectation that one will experience positive outcomes across domains (Scheier \& Carver, 1985). According to Rotter's (1954) Outcome Expectancy Theory, if an individual has optimistic expectations about future success, this influences subsequent behaviour by creating motivation to increase and sustain effort.

With regard to organisations, the construct of PsyCap has become increasingly important as organisations seek to develop and maintain a competitive advantage by enhancing the psychological resources of employees. As mentioned, a growing body of research evidence has indicated that PsyCap is associated with a number of crucial organisational outcomes such as job satisfaction, organisational commitment, effective problem solving and innovative behaviour (Avey, 2014; Choi \& Lee, 2013; Larson \& Luthans, 2006; Luthans, Avey, Clapp-Smith \& Weixing, 2008; Luthans \& Jensen, 2005). High levels of PsyCap are also related to lower levels of stress (Avey, Luthans \& Jensen, 2009) and higher levels of employee engagement (Avey, Wernsing \& Luthans, 2008). Further, PsyCap is a significant predictor of employee performance (Luthans et al., 2007; Luthans et al., 2008). Consequently, it can be seen that there are important implications for organisations to have, within their employment, individuals with a high degree of PsyCap and/or foster the development of PsyCap constructs within their employees. Research has also noted that there are a number of possible antecedents of PsyCap, namely, organisational factors of leadership and supervision, social support at work, and job design characteristics, where jobs are sufficiently challenging but still enable the job incumbent to experience success (Avey, 2014). In addition, individual factors such as personality have been noted as an antecedent affecting levels of PsyCap (Avey, 2014). As SRI consists of stable sex-based personality traits it may be an antecedent factor that could influence levels of PsyCap. Thus, on the basis of these findings, the present study chose to focus on the possible association between SRI and PsyCap. 


\section{The proposed relationship between positive and negative sex role identities and psychological capital}

Previous research on positive SRIs has shown that they are associated with numerous health outcomes; alternatively, negative SRIs have inverse associations with such outcomes.

Positively androgynous individuals evidence greater confidence and self-efficacy, enabling them to adapt to situational demands (Bem, 1975; Woodhill \& Samuels, 2004). Significant positive relationships have also been found between masculinity and self-efficacy, confidence, independence and achievement(Allgood-Merten\&Stockard, 1991; Choi, 2004; Gianakos, 2000; Helgeson, 1994; Hirschy \& Morris, 2002). For those that are positively feminine, research findings have supported superior skills with regard to mobilising and utilising social support (Bernstein, 2013; Bornstein et al., 2002; Kitamura et al., 2002; Neff \& Karney, 2005; Reevy \& Maslach, 2001). Positive identities are also predicted to be positively related to hope (Ghaed \& Gallo, 2006; Kirchmeyer, 1996; Watson, Clark \& Harkness, 1994). Given superior self-efficacy, coping skills, and ability to secure social support, positive identities are also more likely to perceive that they have adequate ability to meet demands and cope with challenges, adapt to stressors and therefore are likely to be more resilient to obstacles (Ghaed \& Gallo, 2006; Gianakos, 2000; Helgeson \& Fritz, 2000; Long, 1989). With regard to optimism, positive identities also report higher use of positive self-talk and positive thinking, suggesting higher optimistic thoughts and expectations (Ghaed \& Gallo, 2006; Helgeson \& Fritz, 2000). All three positive identities also report greater general happiness, levels of well-being and levels of optimism (Gianakos, 2000; Woodhill \& Samuels, 2003).

In contrast, negative identities are associated with poor health outcomes. These include a cluster of negative psychosocial traits such as hostility, aggression or passiveaggressiveness, anger, elevated levels of anxiety and depressive rumination, excessive worrying and in some instances passivity and submissiveness. These identities also display far less self-confidence and self-assurance (Ghaed \& Gallo, 2006; Bernstein, 2013) and are therefore more likely to have a lower sense of self-efficacy. Lowered self-belief can also become a self-fulfilling prophecy with those having negative identities experiencing poor outcomes with regard to goal attainment. Negative identities are also predicted to have lower resilience than the positive identities. The association of these identities with anxiety, negative rumination and depression, in turn, bodes poorly for their ability to cope with and be resilient in the face of adverse circumstances. Poor outcomes attained in relation to goals attainment may also impair levels of hope and optimism in the long term (Aube, 2008; Ghaed \& Gallo, 2006; Helgeson \& Fritz, 1999; Woodhill \& Samuels, 2003; Wupperman \& Neumann, 2006).

\section{Research purpose and objectives}

Based on the psychosocial correlates reported in the literature for positive and negative SRIs, the present study hypothesised that individuals with positive SRIs would have higher levels of PsyCap whereas those with negative SRIs would have lower levels of PsyCap.

Hypothesis 1: Positive SRIs will have high(er) levels of PsyCap.

Hypothesis 2: Negative SRIs will have low(er) levels of PsyCap.

\section{Research design}

\section{Research approach}

The study was conducted as a non-experimental cross-sectional quantitative study, utilising a self-report questionnaire. A between-subjects design was used and groups for the independent variable were based on seven possible SRI categories. Non-probability sampling, namely, convenience sampling was utilised.

\section{Research method}

\section{Research participants}

The target population for this study were individuals currently working in South African organisations, over the age of 18 , with access to a computer and the internet and working in any role other than manual labour or blue collar work. Participants were sourced from various organisations, from social media and from WitsPlus, which consists of students attending night classes who are in full-time employment.

The demographic characteristics of the sample utilised for this study are displayed in Table 1 . The age of respondents

\begin{tabular}{|c|c|c|c|}
\hline Variable & Item & Frequency & $\%$ \\
\hline \multirow[t]{2}{*}{ Gender } & Male & 130 & 27.2 \\
\hline & Female & 348 & 72.8 \\
\hline \multirow[t]{6}{*}{ Population group } & Caucasian & 296 & 61.9 \\
\hline & Black African & 111 & 23.2 \\
\hline & Coloured & 39 & 8.2 \\
\hline & Indian & 28 & 5.9 \\
\hline & Asian & 2 & 0.4 \\
\hline & Other & 2 & 0.4 \\
\hline \multirow[t]{7}{*}{ Job level } & Entry level & 57 & 12.0 \\
\hline & Intermediate & 139 & 29.2 \\
\hline & Junior management & 66 & 13.9 \\
\hline & Middle management & 131 & 27.5 \\
\hline & Upper management & 56 & 11.8 \\
\hline & Executive & 27 & 5.7 \\
\hline & Missing & 2 & 0.4 \\
\hline \multirow{6}{*}{$\begin{array}{l}\text { Sex role identity } \\
\text { composition of } \\
\text { present sample }\end{array}$} & Positive androgyny & 23 & 4.8 \\
\hline & Negative androgyny & 21 & 4.4 \\
\hline & Positive masculinity & 105 & 22.0 \\
\hline & Negative masculinity & 60 & 12.6 \\
\hline & Positive femininity & 118 & 24.7 \\
\hline & Negative femininity & 151 & 31.6 \\
\hline
\end{tabular}

Source: Jacobs, S. (2014). Sex role identity and positive psychological constructs among South African employees. Masters dissertation. Johannesburg, South Africa: University of the Witwatersrand 
ranged from 18 to 74 with a mean age of 37.48. Respondents were predominantly white (61.9\%), English speaking (58.2\%) and female $(72.8 \%)$ and most were in intermediate to middle management $(70.6 \%)$. Table 1 also describes the proportion of respondents who were categorised as belonging to each SRI through their endorsement of specific items on the EPAQ-R. The highest proportion was negatively feminine (31.6\%), followed by positively feminine $(24.7 \%)$, positively masculine $(22 \%)$, negatively masculine $(12.6 \%)$, positively androgynous (4.8\%) and finally negatively androgynous (4.4\%). Only one person reported being undifferentiated, and this individual was excluded from the study given insufficient numbers to run statistical analysis on this identity. The higher proportions of positive and negative femininity were likely to be attributable to the large number of females in the sample.

\section{Measuring instruments}

For this study, a fixed format composite questionnaire was used. This included the EPAQ-R and PCQ-24 instruments, discussed below. Additionally, participants were asked to fill in eight demographic questions with demographics being used purely to describe the sample.

Extended personal attribute questionnaire (revised): The EPAQ-R, modified by Bernstein (2013) was utilised for this study. The EPAQ-R is a self-report questionnaire measuring levels of socially desirable (positive) and socially undesirable (negative) masculine and feminine traits. The revised version, which was utilised in the nine studies conducted within the South African Research Project, as described previously, and within the present study, showed good internal consistencies across all subscales with Cronbach alphas ranging from a minimum of 0.71 to 0.86 across all subscales.

The instrument consists of 57 items and asks respondents to indicate the extent to which each item (a trait adjective) is representative of their behaviour, on a Likert scale from 1 to 5. Each of these items is attributed to one of the four SRI subscales; namely positive masculine, negative masculine, positive feminine and negative feminine. An example of a positively masculine item is 'not at all competitive - very competitive'; an example of a negatively masculine item is 'not at all hostile - very hostile'; an example of a positively feminine item is 'not at all caring - very caring' and an example of a negatively feminine item is 'not at all submissive - very submissive'. To make valid statistical comparisons, all raw scores on the EPAQ-R were converted into $\mathrm{z}$-scores and then classified into one of the seven SRIs. Individuals with high scores on a particular subscale were classified with that SRI, in accordance with the methodology described by Woodhill and Samuels (2003). Respondents with high scores for both positive masculinity and positive femininity were classified as positively androgynous. Those with high scores for both negative masculinity and negative femininity were classified as negatively androgynous. Those with low scores on all subscales were categorised as undifferentiated.
Psychological capital: The PCQ-24 developed by Luthans et al. (2007), is a 24-item questionnaire with each item measured on a 6 -point Likert scale ranging from ' 1 ' being strongly disagree to ' 6 ' being strongly agree. The PCQ-24 is comprised of four subscales, namely; self-efficacy, hope, resilience and optimism, with each subscale containing six items. An example of a self-efficacy item is 'I feel confident analysing a long term problem to find a solution'; an example of hope item is 'I can think of many ways to reach my current work goals'; an example of a resilience item is 'I usually take stressful things at work in stride' and an example of an optimism item is 'When things are uncertain for me at work, I usually expect the best'. The instrument is copyrighted and permission was obtained to use it for research purposes from Mind Garden. In a psychometric review of the PCQ-24, 28 of the 29 studies reported overall Cronbach internal reliability alphas of above 0.70 (Dawkins, Martin, Scott \& Sanderson, 2013). Dawkins et al., (2013) found consistent evidence of a four-factor structure for the PCQ-24, and Görgens-Ekermans and Herbert (2013) validated this instrument in a South African context.

\section{Research procedure and ethical considerations}

Ethical clearance was obtained from the University of the Witwatersrand Ethics Committee. Once obtained, respondents were sourced within organisations, from the social media platform of LinkedIn and from WitsPlus. With regard to organisations, permission was granted from Human Resource (HR) managers and/or HR Directors for the questionnaire to be electronically distributed to employees. Organisations were predominantly sourced from the retail, educational and financial sectors. Once permission was granted, the HR Manager (or relevant Director) sent an email to all employees, which contained an invitation to participate in the study and an encrypted link enabling access to this questionnaire. With regard to social media, a request for participation was posted on South African LinkedIn pages for South African individuals who fulfilled the participation criteria. The posts requested individuals who fulfilled the participation criteria to click on the encrypted link to participate. With regard to WitsPlus, permission was obtained from the WitsPlus course coordinator to approach WitsPlus students. WitsPlus students are individuals who are enrolled in part-time evening classes at the University of the Witwatersrand, studying towards a degree. All of these individuals are in full-time employment. To facilitate electronic collection of data, a composite questionnaire was created on the website Survey Monkey. This online questionnaire included a cover letter, biographical questions and the EPAQ-R and PCQ-24. The cover letter, provided to all participants, briefly outlined the purpose of the study, expected participation time, informed prospective respondents that participation was voluntary, that there were no disadvantages and/or risks for participating and that respondents could withdraw from the study at any point prior to submitting their responses, with submission being regarded as informed consent. The cover letter also stated that each participating organisation would receive a 
summarised report of the entire study, but no organisation or individual could be identified in the summary. This letter also stated that as no identifying information would be collected, all responses would be anonymous. Thus, ethical requirements were deemed to have been met.

\section{Statistical analysis}

Data obtained from the questionnaires were captured using Microsoft Excel (Version 5) and analysed using SPSS Statistics Version 2.0. Analysis to determine descriptive statistics, including means, standard deviations, kurtosis, skewness and Pearson's Product Moment Correlations was conducted. For the purpose of this research, a correlation of 0.10 was considered small, 0.30 moderate and 0.50 and greater was considered large (Cohen, 1988). Cronbach alpha coefficients were calculated for each subscale in the EPAQ-R and PCQ-24. Inferential statistics, including Analysis of Variance (ANOVA) and post-hoc Tukey's tests were conducted. Cohen's d statistic was calculated to determine practical significance. The guidelines used for interpretation of Cohen's $\mathrm{d}$ are that a small effect size is $0.20<|\mathrm{d}|<0.49$, a moderate effect size occurs when $0.50<|\mathrm{d}|<0.80$, and a large effect size occurs when $|\mathrm{d}| \geq 0.80$ (Gravetter \& Wallnau, 2009). Results were considered to be significant at $5 \%$ level of significance.

\section{Results}

\section{Descriptive statistics and Cronbach alpha coefficients}

The key descriptive statistics for the variables under investigation, including the minimum, maximum, mean and standard deviation are summarised in Table 2. Furthermore, the Cronbach alpha for each subscale has been presented in Table 2. It is evident that the EPAQ-R and PCQ-24 both have internal reliabilities greater than the minimum recommended level of 0.60 (Malhotra, 2010). As can be seen in Table 2, data are sufficiently normally distributed, falling between -1 and +1 for both skewness and kurtosis coefficients (Huck, 2012).

\section{Pearson's correlations}

Table 3 shows the correlations between each of the four EPAQ-R subscales, PCQ-24 and the four subscales of PCQ-24 (self-efficacy, hope, resilience, optimism).

Table 3 indicates significant positive moderate to strong correlations between the positive masculine subscale and self-efficacy (0.45), hope (0.43), resilience (0.43), optimism (0.38) and PsyCap (0.53). For positive femininity, there was a significant positive, albeit low correlation to self-efficacy (0.10), resilience (0.15), optimism (0.18) and overall PsyCap (0.15). Scores on the negative masculine subscale had no significant correlations to any PsyCap subscales. The negative femininity subscale had significantly moderate to strong inverse correlations to self-efficacy $(-0.36)$, hope $(-0.39)$, resilience (-0.39), optimism (-0.38) and overall PsyCap (-0.48).

\section{Relationship between sex role identity and psychological capital, self-efficacy, hope, resilience and optimism}

All assumptions were successfully tested for the use of ANOVA to analyse variables in this study. Using one-way ANOVAs, significant results were found between the different SRIs and overall PsyCap, and the different SRIs and each PsyCap variable. These results are shown in Table 4.

Given that all the ANOVAs were significant, Tukey's posthoc tests were conducted to determine which means were significantly different from one another for PsyCap and its subscales. Significant differences between SRIs are presented in Table 5.

TABLE 2: Descriptive statistics for EPAQ-R and PCQ-24.

\begin{tabular}{|c|c|c|c|c|c|c|c|c|}
\hline Variable & Subscale & Min & Max & $\mathbf{M}$ & SD & Skewness & Kurtosis & Cronbach alpha \\
\hline \multirow[t]{4}{*}{ EPAQ-R } & Positive masculinity & 25 & 65 & 47.49 & 7.48 & -0.19 & -0.17 & 0.82 \\
\hline & Negative masculinity & 35.12 & 8.26 & 15 & 60 & 0.17 & -0.34 & 0.83 \\
\hline & Positive femininity & 44.36 & 5.96 & 26 & 55 & -0.33 & -0.38 & 0.83 \\
\hline & Negative femininity & 45.18 & 9.59 & 21 & 79 & 0.23 & 0.08 & 0.84 \\
\hline \multirow[t]{5}{*}{ PCQ-24 } & Self-efficacy & 29.94 & 4.39 & 14 & 36 & -0.76 & 0.62 & 0.85 \\
\hline & Hope & 28.79 & 4.44 & 15 & 36 & -0.50 & 0.11 & 0.82 \\
\hline & Resilience & 28.92 & 3.86 & 13 & 36 & -0.49 & 0.48 & 0.69 \\
\hline & Optimism & 27.28 & 4.31 & 12 & 36 & -0.40 & 0.58 & 0.62 \\
\hline & PCQ-24 total & 71 & 144 & 114.93 & 13.52 & -0.36 & 0.28 & 0.89 \\
\hline
\end{tabular}

$\mathrm{M}$, mean; SD, standard deviation.

Source: Jacobs, S. (2014). Sex role identity and positive psychological constructs among South African employees. Masters dissertation. Johannesburg, South Africa: University of the Witwatersrand

TABLE 3: Correlations between subscales of the EPAQ-R and PCQ-24.

\begin{tabular}{|c|c|c|c|c|c|}
\hline Subscale & Self-efficacy & Hope & Resilience & Optimism & PCQ-24 total \\
\hline $\mathrm{M}+$ & $0.45^{*}$ & $0.43 *$ & $0.43 *$ & $0.38 *$ & $0.53 *$ \\
\hline M- & 0.08 & 0.03 & -0.06 & -0.08 & -0.01 \\
\hline $\mathrm{F}+$ & $0.10^{*}$ & 0.07 & $0.15 *$ & $0.18 *$ & $0.15^{*}$ \\
\hline F- & $-0.36 *$ & $-0.39 *$ & $-0.39 *$ & $-0.38 *$ & $-0.48^{*}$ \\
\hline
\end{tabular}

A-, Negative Androgyny; A+, Positive Androgyny; M+, Positive Masculinity; M-, Negative Masculinity; F+, Positive Femininity; F-, Negative Femininity.

*, Statistically significant correlations at 0.05 level of significance.

Source: Jacobs, S. (2014). Sex role identity and positive psychological constructs among South African employees. Masters dissertation. Johannesburg, South Africa: University of the Witwatersrand 
Results of the post-hoc tests revealed that on the whole there were significant differences between the positive and negative identities on overall PsyCap and on the PsyCap subscales. In addition, there were differences between some of the positive identities and between some of the negative identities. Thus, Hypothesis 1 and Hypothesis 2 were largely supported.

\section{With regard to sex role identity and overall psychological capital}

Positive androgyny and positive masculinity had higher levels of overall PsyCap compared to positive femininity and compared to negative androgyny and negative femininity, whereas positive femininity was only significantly higher than negative femininity. In addition, negative masculinity reported significantly higher PsyCap than negative androgyny and negative femininity. All effect sizes observed were large, except between positive masculinity and positive femininity, which was moderate.

\section{With regard to sex role identity and self-efficacy}

Positive androgyny was found to be significantly higher, than negative androgyny and negative femininity, whereas positive masculinity and positive femininity had a significantly higher mean than negative femininity only. Negative masculinity also reported a significantly higher mean than negative femininity. In terms of effect sizes, a moderate effect size was reported for the difference between positive and negative femininity. All the other effect sizes observed were large.

\section{With regard to sex role identity and hope}

Positive androgyny was significantly higher than negative androgyny and negative femininity. Positive masculinity was

TABLE 4: One-way ANOVA results.

\begin{tabular}{lcc}
\hline Comparison & \multicolumn{2}{c}{ ANOVA } \\
\cline { 2 - 3 } & $\boldsymbol{F}$ & $\boldsymbol{p}$ \\
\hline SRI and PsyCap & 27.15 & 0.00 \\
SRI and self-efficacy & 18.03 & 0.00 \\
SRI and hope & 13.99 & 0.00 \\
SRI and resilience & 17.44 & 0.00 \\
SRI and optimism & 15.98 & 0.00 \\
\hline
\end{tabular}

Source: Jacobs, S. (2014). Sex role identity and positive psychological constructs among South African employees. Masters dissertation. Johannesburg, South Africa: University of the Witwatersrand significantly higher than positive femininity, negative androgyny and negative femininity. Negative masculinity was found to be significantly higher than negative femininity and finally positive femininity reported a significantly higher mean than negative femininity. The only significant difference found between the positive identities was between positive masculinity and positive femininity. Finally, no significant differences were found between the positive identities and negative masculinity. The effect size between positive masculinity and positive femininity, and between positive femininity and negative femininity, were all moderate. The Cohen's d effect sizes for all remaining post-hoc test differences between means were all large.

\section{With regard to sex role identity and resilience}

Positive androgyny was significantly higher than positive femininity, negative androgyny and negative femininity. Positive masculinity was significantly higher than negative androgyny and negative femininity. Similarly, negative masculinity was significantly higher than negative androgyny and negative femininity. Lastly, positive femininity reported a significantly higher mean than negative femininity for levels of resilience. Effect sizes for all comparisons were large, except between positive and negative femininity, which was moderate.

\section{With regard to sex role identity and optimism}

Positive androgyny had a significantly higher mean than both negative androgyny and negative femininity. Positive masculinity had a higher mean than negative masculinity, negative androgyny and negative femininity. Similarly, the mean for negative masculinity was significantly greater than the mean for negative femininity. Additionally, positive femininity had a significantly higher mean than negative femininity. In terms of effect sizes, moderate effect sizes were reported between positive and negative masculinity and negative masculinity and femininity. All other effect sizes for the post-hoc tests were large.

\section{Discussion}

Overall, the findings within the present research largely supported the research hypothesis that those with positive

TABLE 5: Tukey's post-hoc tests: SRI, PsyCap, self-efficacy, hope, resilience and optimism.

\begin{tabular}{|c|c|c|c|c|c|c|c|c|c|c|}
\hline \multirow[t]{2}{*}{ SRI comparison } & \multicolumn{2}{|c|}{ PsyCap } & \multicolumn{2}{|c|}{ Self-efficacy } & \multicolumn{2}{|c|}{ Hope } & \multicolumn{2}{|c|}{ Resilience } & \multicolumn{2}{|c|}{ Optimism } \\
\hline & $\begin{array}{c}\text { Mean } \\
\text { difference }\end{array}$ & Cohen's d & $\begin{array}{c}\text { Mean } \\
\text { difference }\end{array}$ & Cohen's d & $\begin{array}{c}\text { Mean } \\
\text { difference }\end{array}$ & Cohen's d & $\begin{array}{c}\text { Mean } \\
\text { difference }\end{array}$ & Cohen's d & $\begin{array}{c}\text { Mean } \\
\text { difference }\end{array}$ & Cohen's d \\
\hline$A+$ and $A-$ & 16.92 & 1.33 & 3.55 & 0.77 & 4.30 & 0.91 & 4.95 & 1.36 & 4.12 & 0.89 \\
\hline $\mathrm{A}+$ and $\mathrm{F}+$ & 9.06 & 0.73 & - & - & - & - & 2.63 & 0.77 & - & - \\
\hline $\mathrm{A}+$ and $\mathrm{F}-$ & 19.13 & 1.45 & 5.18 & 1.12 & 4.51 & 0.56 & 4.98 & 1.41 & 4.46 & 0.90 \\
\hline $\mathrm{M}+$ and $\mathrm{F}+$ & 4.83 & 0.43 & - & - & 1.67 & 0.42 & - & - & - & - \\
\hline $\mathrm{M}+$ and $\mathrm{M}-$ & - & - & - & - & - & - & - & - & 2.05 & 0.56 \\
\hline $\mathrm{M}+$ and $\mathrm{A}-$ & 12.70 & 1.09 & - & - & 3.60 & 0.80 & 3.16 & 0.85 & 3.54 & 1.02 \\
\hline $\mathrm{M}+$ and $\mathrm{F}-$ & 14.91 & 1.22 & 4.03 & 0.97 & 3.81 & 0.89 & 3.19 & 0.88 & 3.88 & 1.00 \\
\hline M- and A- & 9.41 & 0.83 & - & - & - & - & 2.95 & 0.84 & - & - \\
\hline $\mathrm{M}$ - and $\mathrm{F}$ - & 11.62 & 0.98 & 3.90 & 1.00 & 2.92 & 0.73 & 2.98 & 0.87 & 1.83 & 0.46 \\
\hline $\mathrm{F}+$ and $\mathrm{F}-$ & 10.08 & 0.81 & 2.62 & 0.63 & 2.14 & 0.50 & 2.35 & 0.63 & 2.97 & 0.72 \\
\hline
\end{tabular}

A-, Negative Androgyny; A+, Positive Androgyny; M+, Positive Masculinity; M-, Negative Masculinity; F+, Positive Femininity; F-, Negative Femininity.

Source: Jacobs, S. (2014). Sex role identity and positive psychological constructs among South African employees. Masters dissertation. Johannesburg, South Africa: University of the Witwatersrand 
SRIs, particularly positive androgyny and positive masculinity, had higher levels of PsyCap than those with negative SRIs. More specifically for PsyCap, and each of its constructs, positive androgyny and positive masculinity showed consistently higher health outcomes than negative androgyny and negative femininity. Finding higher selfefficacy for positive identities is consistent with existing literature and theory. Self-efficacy is strongly related to and reinforced by prior successes or failures in similar domains (Bandura, 1997). Positive characteristics, particularly agentic, positively masculine traits are often highly valued in the work domain and therefore associated with more successful outcomes, compared to traits of negative femininity and negative androgyny (Mueller, 2008; Welle \& Heilman, 2007). These superior outcomes are perpetuated by reinforcing confidence and self-efficacy, which further support superior outcomes (Bandura, 1977, 1982). The corollary of this, however, is the downward spiral of negative identities, particularly negative femininity. This identity has lower confidence and self-efficacy, which may lead to poor results, which in turn, further reduces confidence and self-efficacy (Ghaed \& Gallo, 2006; Helgeson \& Fritz, 2000; Spence et al., 1979; Watson et al., 1994). For levels of hope, the superior outcomes for positive identities compared to negative femininity and negative androgyny also aligns with previous research. The positive SRI traits of greater agency, conscientiousness, internal locus of control and positive appraisals of future challenges are all associated with higher levels of hope, both in the present and the future (Ghaed \& Gallo, 2006; Gianakos, 2002; Sarrasin, Mayor \& Faniko, 2014; Watson et al., 1994). In terms of resilience, individuals with positive identities tend to be more able to successfully develop and embed themselves in social networks and thereby they experience enhanced resilience as their networks bolster them in times of duress. Furthermore, positive SRIs appraise demands more in terms of challenges as opposed to threats and they are therefore more likely able to effectively manage stress and utilise greater problem-focused coping skills compared to individuals with negative identities (Chow, 1987; Ghaed \& Gallo, 2006; Gianakos, 2000; Helgeson, 1994; Helgeson \& Fritz, 1999, 2000; Lam \& McBride-Chang, 2007). Higher levels of optimism for positive identities are also consistent with empirical findings, given that positive identities report greater less perceived work stress, higher psychological well-being, self-esteem, social support, general happiness and greater positive thinking than negative identities (Bernstein, 2013; Chemaly, 2012, 2013; De Freitas, 2013, 2014; Gianakos, 2000; Kilgour, 2014; Solomon, 2012; Sugden, 2014; Woodhill \& Samuels, 2003).

The poor outcomes of those with negative identities in relation to PsyCap are also aligned with previous research findings. Research has shown that individuals embracing negative identities have a lesser ability to build effective long-term supportive interpersonal relationships (Ghaed \& Gallo, 2006; Netuveli, Wiggins, Montgomery, Hildon \& Blane, 2008). In particular, negative femininity is associated with high levels of neuroticism, lower coping abilities and resources, and greater perceptions of demands as threatening and therefore as stressors (Watson et al., 1994). They also tend to be overly demanding of their support networks which over time can lead to a reduction in support resources, all of which can serve to decrease resilience in the face of hardships and challenges (Aube, 2008; Helgeson, 1994). The poor performance of negative femininity and negative androgyny on optimism aligns with previous research, including research conducted within the South African context in which negatively feminine traits are associated with lower psychological well-being, lower EQ, optimism, social support and greater perceived stress, work-family conflict, anxiety, depression and neuroticism (Aube, 2008; Bernstein, 2013; Chemaly, 2012, 2013; De Freitas, 2013, 2014; Ghaed \& Gallo, 2006; Kilgour, 2014; Solomon, 2012; Sugden, 2014; Woodhill \& Samuels, 2003, 2004).

Furthermore, it was notable that the findings for the SRI of negative masculinity were counterintuitive to the hypothesis for this SRI. In all instances, (with the exception of a significant difference between positive masculinity and negative masculinity on optimism) none of the positive identities enjoyed significantly higher levels of PsyCap as compared to negative masculinity, and negative masculinity often times experienced significantly higher PsyCap than negative femininity and negative androgyny. Furthermore, for PsyCap, hope and resilience, negative masculinity reported significantly higher means than positive femininity. These findings were contrary to those reported in international research, where the traits of negative masculinity have been associated with a wide range of deleterious outcomes, including greater verbal and physical aggression, interpersonal problems, and elevated levels of anxiety, depression, anger and social conflict (Ghaed \& Gallo, 2006; Helgeson \& Fritz, 1999, 2000). These counterintuitive findings may be attributable to the South African cultural acceptance of and even admiration of 'hegemonic masculinity'. Hegemonic masculinity is used to describe one form of masculinity that is dominant in terms of power relations in society (Connell \& Messerschmidt, 2005). An evaluation of the traits of hegemonic masculinity, that is, traits such of dominance, male control and power, aggression, and hostility (Buss, 1990; Ghaed \& Gallo, 2006; Helgeson \& Fritz, 1999) highlights strong similarities with the negative masculine SRI. Hegemonic masculinity is ideologically embedded in South African culture and accepted as a cultural prototype for masculinity (Cockburn, 1983; Connell \& Messerschmidt, 2005; Groes-Green, 2009; Herdt, 1981; Morell, Jewkes \& Lindegger, 2012). These types of behaviours have been endorsed through a combination of culturally accepted patriarchy, traditional masculine ideas and religious practices (Coetzee, 2001). For example in South Africa, traditional masculine roles of aggression, coercion, arrogance, dominance and superiority are socially present, accepted and even seen as beneficial (Thaler, 2011). These particular traits, used to assert masculinity and maintain power have been documented across the country (Jewkes, Levin \& Penn-Kekana, 2003; Jewkes, Penn-Kekana, Levin, Ratsaka \& 
Schrieber, 2001; Strebel et al., 2006; Thaler, 2011). Given that so-called negatively masculine traits are considered acceptable and even desirable in South African society, this could explain the more positive outcomes of the negatively masculine identity in South Africa as compared to other sociocultural contexts. Although there have been new social and political influences since the fall of Apartheid, the masculine traits of dominance, aggression and control are still traits regarded positively by many South Africans (Langa, 2012). These more beneficial outcomes for the negatively masculine identity in this study align with other SRI research previously conducted in the South African Research Project (Berman, 2013; Bernstein, 2013; Chemaly, 2012, 2013; DeFreitas, 2013, 2014; Kilgour, 2014; Solomon, 2012; Sugden, 2014). It is therefore possible that sociocultural factors, unique to South Africa, may have contributed to these findings. It would thus be of interest if future research in South Africa, utilising both quantitative and qualitative methodologies, could explore both the 'meaning' and the desirability of 'so-called negative' masculine traits.

\section{Practical implications of the sex role identity- psychological capital relationship for organisations}

Given the research implications of SRI and PsyCap for organisational well-being, these findings on the interrelationship between SRI and PsyCap have important implications for organisations. Should South African organisations choose to utilise a SRI framework, the EPAQ-R which in fact measures sex-based personality traits, provides interesting insights into employees, similar to the use of other personality instruments. Personality testing is often used in organisations as a tool for recruitment, selection, placement and leadership development and for identifying those with specific training needs or those in need of workplace counselling interventions; and it may well be possible that a tool such as the EPAQ-R can be utilised, (along with other assessment criteria) as a valuable diagnostic instrument. With regard to recruitment and selection, the identification of individuals with negative SRIs could serve as a screening tool to avoid appointing individuals whose negative traits could be associated with lower levels of PsyCap and in turn their ability to function adequately if not optimally within a particular position (Jacobs, 2014). Similarly, the identification of individuals with positive SRIs could serve as a tool to singling out individuals with specific personality traits that are desirable to the organisation.

As many organisations do use personality inventories as recruitment and selection tools that screen for negative personality types and subclinical levels of psychopathology, such as, anxiety, aggression, passivity, withdrawal behaviours, introversion, lack of conscientiousness and neuroticism; the EPAQ-R could serve as a valuable diagnostic tool. Its value as a diagnostic tool lies in its sound psychometric properties and its ability to capture traits that are associated with a wide range of positive and negative socio-emotional correlates. In this regard, research has indicated that the instrument and its subscales have sound psychometric properties (Bernstein, 2013; Bernstein \& Osman, 2016). In addition, it has demonstrated its strong predictive ability in relation to a whole host of outcome variables that are of major importance within the work domain. For example, research conducted across the nine studies within the South African Research Project utilising the EPAQ-R demonstrated that those with positive identities report significantly lower perceptions of work stress, workfamily conflict, and pessimism and significantly higher psychological well-being, self-esteem, social support, conflict resolution skills, emotional intelligence, work engagement, perceived organisational support and perceived insider status, as compared to those with negative identities (see Bernstein \& Osman, 2016).

Furthermore, researchers have demonstrated that positive and negative SRIs have a number of socio-emotional correlates which are captured by and measured when using SRI scales. Examples of socio-emotional correlates described in research for positive identities are strong associations with better interpersonal and social skills and leadership ability, the latter more so especially for masculine and androgynous individuals, whereas femininity is associated with greater degree of warmth and nurturance. All of the positive identities are associated with greater, albeit varying degrees of agreeableness, conscientiousness and gregariousness as compared to negative identities. Socio-emotional correlates for negative identities are greater aggressiveness and hostility, authoritarianism and lower conscientiousness and agreeableness for negative masculinity, whereas negative femininity is associated with being overly agreeable, passive, submissive, and high degrees of neuroticism, anxiety and depression.

Thus, the EPAQ-R, which is a relatively compact, psychometrically sound instrument, consisting of only 57 items is potentially able to capture many of these socioemotional correlates that are important to organisational outcomes. As such, the EPAQ-R may have an advantage over the use of large batteries or lengthy personality inventories as it collates many of constructs requiring assessment and of importance to organisations into a single diagnostic tool.

The EPAQ-R also has utility for existing employees. For individuals already within employment, to the extent that their negative traits could currently be exerting a deleterious impact on their ability to function within their jobs, so could counselling interventions be put into place to help them manage these traits more effectively. Training and development could also be utilised for individuals in an attempt to foster and promote the development of more positive traits and more positive attitudes within individuals, so as to enhance organisational effectiveness (Jacobs, 2014).

\section{Limitations and recommendations}

Despite the significant findings, there are a number of limitations that must be acknowledged. The sample used in 
this research included respondents from a range of different industries and organisations and consequently the culture of each organisation was not examined. Organisational culture may vary to the extent that it embodies more masculine or feminine values or is more communally or individualistically orientated (Hofstede, 1983). The organisation's culture may therefore have an impact on the individual outcomes for different SRIs (Korac-Kakabadse \& Kouzmin, 1997). Future research could examine organisational culture, the degree of fit between culture and SRI and the implications of fit or lack of fit for individual and organisational well-being. In this regard the EPAQ-R can be used to determine whether an individual's sex-based traits are aligned to organisational values. Although it has been argued that greater value is placed upon masculine traits within organisations, this is not always the case. For example, in certain professions, such as nursing and teaching where feminine values of compassion, concern for others and caring are promoted, feminine traits may have greater value and the EPAQ-R could be utilised to evaluate the strength of individuals in these traits. To the extent that one's traits are aligned with job requirements and organisational values, so may this enhance the individual's ability to function 'successfully' within the job, which in turn may enhance an individual's levels of job-related PsyCap. As there has been, to the authors' knowledge, no research done on utilising SRI instruments for such purpose within organisations, the efficacy of such interventions remains to be explored in future research.

A further limitation was that the sample was not balanced in terms of the characteristics of respondents. There were 348 females compared to 130 male respondents and there were very few Indian and Asian respondents. A more gender equivalent and diverse sample should be considered for future research in order to enhance the generalisability of the findings. In addition, the research used a non-experimental cross-sectional design. Therefore, no causal relationship could be established. Finally, given that information was collected at a single point in time using a single source, this may have led to an increase in common method variance (Newman, Ucbasaran, Zhu \& Huirst, 2014).

As mentioned, of particular interest was the finding for negative masculinity within the present sample along with all other samples within the South African Research Project which suggests a need to further explore the 'meaning', typicality and desirability, of negatively masculine traits within the South African context

\section{Conclusion}

This study provides a unique contribution to existing literature by examining both positive and negative SRIs and their relationship to the positive psychological outcomes of self-efficacy, hope, resilience and optimism in a South African organisational context. To the authors' knowledge no research has been done outside of the South African Research Project on the implications of both positive and negative SRIs for crucial organisational outcome variables. Consequently, this study, by examining the association between positive and negative SRIs and PsyCap, and the practical implications thereof, adds to a body of knowledge that seeks to enhance individual and organisational outcomes. The findings of this research have implications for organisations in terms of providing a practical means of assessing individuals' behavioural traits and of aligning their selection and placement into positions in which their traits will be appropriately matched with the culture of the organisation and/or the requirements of the job. In addition, by selecting individuals with the 'right' characteristics, this could contribute to employment of individuals with concomitantly higher levels of PsyCap, thereby possibly promoting the positive organisational outcome variables attendant with this psychological construct.

\section{Acknowledgements Competing interests}

The authors declare that they have no financial or personal relationships which may have inappropriately influenced them in writing this article.

\section{Authors' contributions}

C.B. was the research supervisor and project leader of the South African Research Project. S.V. collected and analysed the data as part of her degree of Masters in Organisational Psychology and her study formed part of the larger research project. Both C.B. and S.V. contributed to the writing of the manuscript.

\section{References}

Allgood-Merten, B., \& Stockard, J. (1991). Sex role identity and self-esteem: A comparison of children and adolescents. Sex Roles, 25(3/4), 129-139. http:// dx.doi.org/10.1007/BF00289850

Athenstaedt, U. (2003). On the content and structure of the gender role self-concept: Including gender stereotypical behaviors in addition to traits. Psychology of Women Quarterly, 27(4), 309-318.

Aube, J. (2008). Balancing concern for other with concern for self: Links between unmitigated communion, communion, and psychological well-being. Journal of Personality, 76(1), 101-133. http://dx.doi.org/10.1111/j.1467-6494.2007.00481.x

Avey, J., Wernsing, T.S., \& Luthans, F. (2008). Can positive employees help positive organizational change? Impact of psychological capital and emotions on relevant attitudes and behaviours. The Journal of Applied Behavioural Science, 44(1) 48-70. http://dx.doi.org/10.1177/0021886307311470

Avey, J.B. (2014). The left side of psychological capital: New evidence on the antecedents of PsyCap. Journal of Leadership and Organizational Studies, 21(2), 141-149. http://dx.doi.org/10.1177/1548051813515516

Avey, J.B., Luthans, F., \& Jensen, S.M. (2009). Psychological capital: A positive resource for combating employee stress and turnover. Human Resource Management, 48(5), 677-693. http://dx.doi.org/10.1002/hrm.20294

Avey, J.B., Luthans, F., Smith, R.M. \& palmer, N.F. (2010). Impact of positive psychological capital on employee well-being over time. Journal of Occupational Health Psychology, 15(1), 17-28.

Bandura, A. (1977). Self-efficacy: Towards a unifying theory of behavioral change. Psychological Review, 84(2), 191-215. http://dx.doi.org/10.1037/0033-295X.84. 2.191

Bandura, A. (1982). Self-efficacy mechanism in human agency. American Psychologist 37(2), 122-147. http://dx.doi.org/10.1037/0003-066X.37.2.122

Bandura, A. (1997). Self-efficacy: The exercise of control. New York: W.H. Freeman and Company.

Bem, S.L. (1974). The measurement of psychological androgyny. Journal of Consulting and Clinical Psychology, 42(2), 155-162. http://dx.doi.org/10.1037/h0036215

Bem, S.L. (1975). Sex role adaptability: One consequence of psychological androgyny. Journal of Personality and Social Psychology, 31(4), 634-643. http://dx.doi. org/10.1037/h0077098 
Berger, A., \& Krahe, B. (2013). Negative attributes are gendered too: Conceptualizing and measuring positive and negative facets of sex-role identity. European Journal of Social Psychology, 43(6), 516-531. http://dx.doi.org/10.1002/ejsp.1970

Berman, G. (2013). Sex role identity and preferences for organisational culture. Honours dissertation. Johannesburg, South Africa: University of the Witwatersrand.

Bernstein, C. (2013). The relationship between patterns of sex role identity, work stress, social support and wellbeing in South African female managers. Unpublished doctoral dissertation. Johannesburg, South Africa: University of the Witwatersrand

Bernstein, C., \& Osman, R. (2015). Positives and negatives: Reconceptualizing gende attributes within the context of the sex role identity and wellbeing literature: An examination within the South African context. SA Journal of Industrial Psychology/ SA Tydskrif vir Bedryfsielkunde, 41(1), Art. \#1309. http://dx.doi.org/10.4102/sajip. v41i1.1309

Borna, S., \& White, G. (2003). 'Sex' and 'gender': Two confused and confusing concepts in the 'Women in corporate management' literature. Journal of Business Ethics, 47(2), 89-97. http://dx.doi.org/10.1023/A:1026082400801

Bornstein, R. F., Geiselman, K. J., Eisenhurst, E. A., \& Languirand, M.A. (2002) Construct validity of the Relationship Profile Test: Links with attachment, identity, relatedness, and affect. Assessment, 9(4), 373-381.

Buss, D.M. (1990). Unmitigated agency and unmitigated communion: An analysis of the negative components of masculinity and femininity. Sex Roles, 22(9-10), 555-568. http://dx.doi.org/10.1007/BF00288234

Chemaly, C. (2012). The relationship between positive and negative sex role identities, stress, wellbeing and self-esteem in first year South African University Students. Unpublished Honours dissertation. Johannesburg, South Africa: University of the Witwatersrand.

Chemaly, C. (2013). Positive and negative sex role identities, conflict management styles and psychological wellbeing. Unpublished Masters dissertation. Johannesburg, South Africa: University of the Witwatersrand.

Cheng, C. (1999). Gender role differences in susceptibility to the influence of support availability on depression. Journal of Personality, 67(3), 439-467. http://dx.doi. org/10.1111/1467-6494.00061

Choi, N. (2004). Sex role group differences in specific, academic and general selfefficacy. The Journal of Psychology: Interdisciplinary and Applied, 138(2), 149-159. http://dx.doi.org/10.3200/JRLP.138.2.149-159

Choi, Y., \& Lee, D. (2013). Psychological capital, big five traits and employee outcomes. Journal of Managerial Psychology, 29(2), 122-140. http://dx.doi.org/10.1108/ JMP-06-2012-0193

Chow, E.N. (1987). The influence of sex-role identity and occupational attainment on the psychological well-being of Asian American women. Psychology of Women Quarterly, 11, 69-82. http://dx.doi.org/10.1111/j.1471-6402.1987.tb00775.x

Cockburn, C. (1983). Brothers: Male dominance and technological change. London: Pluto.

Cohen, J. (1988). Statistical power analysis for the behavioral sciences $\left(2^{\text {nd }} E d\right.$.) Hillsdale, NJ: Erlsbaum

Coetzee, D. (2001). South African education and the ideology of patriarchy. South African Journal of Education, 21(4), 300-304.

Connell, R.W., \& Messerschmidt, J.W. (2005). Hegemonic masculinity: Rethinking the concept. Gender and Society, 19(6), 829-859. http://dx.doi.org/10.1177/ 0891243205278639

Dawkins, S., Martin, A., Scott, J., \& Sanderson, K. (2013). Building on the positives: A psychometric review and critical analysis of the construct of Psychological Capital. Journal of Occupational and Organizational Psychology, 86(3), 348-370. http:// dx.doi.org/10.1111/joop.12007

DeFreitas, D. (2013). Variations in sex role identity, sexual orientation, perceived insider status and perceived organisational support among South African male employees. Honours dissertation. Johannesburg, South Africa: University of the Witwatersrand.

DeFreitas, D. (2014). Sex role identity, emotional intelligence and satisfaction at work Masters dissertation. Johannesburg, South Africa: University of the Witwatersrand.

Flaherty, J. F., \& Dusek, J.B. (1980). An investigation of the relationship between psychological androgyny and components of self-concept. Journal of Personality and Social Psychology, 38, 984-992.

Gergen, M.M., \& Davis, S.N. (1997). Towards a new psychology of gender. New York: Routledge.

Ghaed, S.G., \& Gallo, L.C. (2006). Distinctions among agency, communion, and unmitigated agency and communion according to the interpersonal circumplex model, five-factor model and socio-emotional correlates. Journal of Personality model, five-factor model and socio-emotional correlates. Journal of Person
Assessment, 86(1), 77-88. http://dx.doi.org/10.1207/s15327752jpa8601_09

Gianakos, I. (2000). Gender roles and coping with stress. Sex roles, 42(11/12), 1059-1079. http://dx.doi.org/10.1023/A:1007092718727

Gianakos, I. (2002). Predictors of coping with work stress: The influences of sex gender role, social desirability, and locus of control. Sex Roles, 46(5/6), 149-158. http://dx.doi.org/10.1023/A:1019675218338

Görgens-Ekermans, G., \& Herbert, M. (2013). Psychological capital: Internal and external validity of the Psychological Capital Questionnaire (PCQ-24) on a South African sample. SA Journal of Industrial Psychology, 39(2), 1-12. http://dx.doi. org/10.4102/sajip.v39i2.1131

Gravetter, F.J., \& Wallnau, L.B. (2009). Statistics for the behavioural sciences. (8th edn) Belmont, CA: Wadsworth Cengage Learning.

Groes- Green, C. (2009). Hegemonic and subordinated masculinities: Class, violence and sexual performance among young Mozambican men. Nordic Journal of African Studies, 18(4), 286-304.
Guastello, D., \& Guastello, S. (2003). Androgyny, gender role behavior, and emotional intelligence among college students and their parents. Sex Roles, 49(11-12), 663-673. http://dx.doi.org/10.1023/B:SERS.0000003136.67714.04

Heilman, M.E. (2012). Gender stereotypes and workplace bias. Research in Organisational Behaviour, 32, 113-135. http://dx.doi.org/10.1016/j.riob.2012. 11.003

Helgeson, V.S. (1994). Relation of agency and communion to well-being: Evidence and potential explanations. Psychological Bulletin, 6(3), 412-428. http://dx.doi. org/10.1037/0033-2909.116.3.412

Helgeson, V.S., \& Fritz, H.L. (1999). Unmitigated agency and unmitigated communion: Distinctions from agency and communion. Journal of Research in Personality, 33, 131-158. http://dx.doi.org/10.1006/jrpe.1999.2241

Helgeson, V.S., \& Fritz, H.L. (2000). The implications of unmitigated agency and unmitigated communion for domains of problem behaviour. Journal of Personality 68(6), 1031-1057. http://dx.doi.org/10.1111/1467-6494.00125

Helmreich, R.L., Spence, J.T., \& Wilheim, J.A. (1981). A psychometric analysis of the personal attributes questionnaires. Sex Roles, 7, 1097-1108. http://dx.doi. org/10.1007/bf00287587

Herdt, G.H. (1981). Guardians of the flutes: Idioms of masculinity. New York: McGraw-Hill.

Hirschy, A.J., \& Morris, J.R. (2002). Individual differences in attributional style: The relational influence of self-efficacy, self-esteem and sex role identity. Personality and Individual Differences, 32(2), 183-196. http://dx.doi.org/10.1016/S01918869(01)00003-4

Hofstede, G. (1983). The cultural relativity of organizational practices and theories Journal of International Business Studies, 14(2), 75-89. http://dx.doi.org/10.1057/ palgrave.jibs.8490867

Huck, S.W. (2012). Reading statistics and research. (6th edn.). Boston, MA: Pearson Education.

Jacobs, S. (2014). Sex role identity and positive psychological constructs among South African employees. Masters dissertation. Johannesburg, South Africa: University of the Witwatersrand.

Jewkes, R., Levin, L., \& Penn-Kekana, L. (2003). Gender inequalities, intimate partner violence and HIV prevention practices: Findings of a South African cross-sectional study. Social Science and Medicine, 56(1), 125-134. http://dx.doi.org/10.1016/ S0277-9536(02)00012-6

Jewkes, R., Penn-Kekana, L., Levin, J., Ratsaka, M., \& Schrieber, M. (2001). Prevalence of emotional, physical, and sexual abuse of women in three South African provinces. South African Medical Journal, 91, 421-428.

Johnson, J., Greaves, L., \& Repta, R. (2007). Better science with sex and gender: A primer for health research (pp. 1-30). Vancouver: Women's Health Research Network.

Jurma, W., \& Powell, M. (1994). Perceived gender roles of managers and effective conflict management. Psychological Reports, 74(1), 104-106. http://dx.doi. org/10.2466/pr0.1994.74.1.104

Keller, C., Lavish, L., \& Brown, C. (2007). Creative styles and gender roles in undergraduates students. Creativity Research Journal, 19(2/3), 273-280. http:// dx.doi.org/10.1080/10400410701397396

Kilgour, A. (2014). Sex role identity, dispositional optimism and pessimism and perceptions of academic stress among first year university students. Honours dissertation. Johannesburg, South Africa: University of the Witwatersrand.

Kirchmeyer, C. (1996). Gender roles and decision-making in demographically diverse groups: A case for reviving androgyny. Sex Roles, 34(9/10), 649-663. http://dx.doi. org/10.1007/BF01551500

Kitamura, T., Wantanabe, K., Takara, N., Hiyama, K., Yasumiya, R., \& Fujihara, S. (2002). Precedents of perceived social support: Personality, early life experiences, and gender. Psychiatry and Clinical Neurosciences, 56, 169-176.

Korac-Kakabadse, N., \& Kouzmin, A. (1997). Maintaining the rage: From glass and concrete ceilings and metaphorical sex change to psychological audits and renegotiating organizational scripts-part 2. Women in Management Review, 12(6), 207-221. http://dx.doi.org/10.1108/09649429710182422

Lam, C.B., \& McBride-Chang, C.A. (2007). Resilience in young adulthood: The moderating influences of gender-related traits and coping flexibility. Sex Roles, 56 , 159-172. http://dx.doi.org/10.1007/s11199-006-9159-z

Langa, M. (2012). Becoming a man: Exploring multiple voices of masculinity amongst a group of young adolescent boys in Alexandra Township, South Africa. Unpublished doctoral dissertation. Johannesburg, South Africa: University of the Witwatersrand.

Larson, M., \& Luthans, F. (2006). Potential added value of psychological capital in predicting work attitudes. Journal of Leadership and Organization Studies, 13(1) 45-62. http://dx.doi.org/10.1177/10717919070130020601

Lassk, F.G., Kennedy, K.N., Powell, C.M., \& Lagace, R.R. (1992). Psychological adaptiveness and sales managers' job performance. Journal of Social Behavior \& Personality, 7(4), 611-620.

Long, B.C. (1989). Sex-role orientation, coping strategies, and self-efficacy in women in traditional and non-traditional occupations. Psychology of Women Quarterly, 13 307-324. http://dx.doi.org/10.1111/j.1471-6402.1989.tb01004.x

Luthans, F., Avey, J.B., Avolio, B.J., Norman, S.M., \& Combs, G.J. (2007). Psychological capital development: Toward a micro-intervention. Journal of Organizational Behavior, 27, 387-393. http://dx.doi.org/10.1002/job.373

Luthans, F., Avey, J.B., Clapp-Smith, R., \& Weixing, L. (2008). More evidence of the value of Chinese workers' psychological capital: A potentially unlimited competitive resource. The International Journal of Human Resource Management, 19(5), 818-827. http://dx.doi.org/10.1080/09585190801991194 
Luthans, F., Avolio, B.J., Avey, J.B., \& Norman, S.M. (2007). Positive psychological capital: Measurement and relationship with performance and satisfaction. Personnel Psychology, 60, 541-572. http://dx.doi.org/10.1111/j.1744-6570.2007.00083.x

Luthans, F., \& Youssef, C.M. (2004). Human, social, and now positive psychological capital management: Investing in people for competitive advantage. Organizational Dynamics, 33(2), 143-160. http://dx.doi.org/10.1016/j.orgdyn.2004.01.003

Luthans, K.W., \& Jensen, S.M. (2005). The linkage between psychological capital and commitment to organizational mission. Journal of Nursing Administration, 35, 304-310. http://dx.doi.org/10.1097/00005110-200506000-00007

Malhotra, N. K. (2010). Marketing Research: An Applied Orientation (6th ed). Uppe Saddle River, NJ: Pearson.

May, A., \& Spangenberg, J. (1997). Androgyny and coping in men with a manageria orientation. South African Journal of Psychology, 27(4), 244-249. http://dx.doi. org/10.1177/008124639702700407

McCreary, D.R., \& and Korabik, K. (1994). Examining the relationship between the socially desirable and undesirable aspects of agency and communion. Sex Roles, 31(11-12), 637-651. http://dx.doi.org/10.1007/BF01544285

Morell, R., Jewkes, R., \& Lindegger, G. (2012). Hegemonic masculinity/masculinities in South Africa: Culture, power and gender politics. Men and Masculinities, 15(1) 68-79. http://dx.doi.org/10.1177/1097184x12438001

Mueller, S.L. (2008). Gender-role orientation as a determinant of entrepreneurial selfefficacy. Journal of Developmental Entrepreneurship, 13(1), 3-20. http://dx.doi. org/10.1142/S108494670800082X

Neff, L.A. \& Karney, B.R. (2005).Gender differences in social support: A question of skill or responsiveness? Journal of Personality and Social Psychology, 88(1), 79-90.

Netuveli, G., Wiggins, R.D., Montgomery, S.M., Hildon, Z., \& Blane, D. (2008). Mental health and resilience at older ages: Bouncing back after adversity in the British Household Panel Survey. Journal of Epidemiology \& Community Health, 62(11) 987-991. http://dx.doi.org/10.1136/jech.2007.069138

Newman, A., Ucbasaran, D., Zhu, F.E.I., \& Hirst, G. (2014). Psychological capital : A review and synthesis. Journal of Organizational Behavior, 35, 120-138. http:// dx.doi.org/10.1002/job.1916

Reevy, G. M., \& Maslach, C. (2001) Use of social support: Gender and personality differences. Sex Roles, 44 (7/8), 437-460.

Ricciardelli, L.A., \& Williams, R.J. (1995). Desirable and undesirable gender traits in three behavioural domains. Sex Roles, 33(9/10), 637-655. http://dx.doi. org/10.1007/BF01547722

Rotter, J.B. (1954). Social learning and clinical psychology. New York: Prentice-Hall.

Sarrasin, O., Mayor, E., \& Faniko, K. (2014). Gender traits and cognitive appraisal in young adults: The mediating role of locus of control. Sex Roles, 70, 122-133. $\mathrm{http}: / / \mathrm{dx}$.doi.org/10.1007/s11199-013-0336-6

Schaufeli, W.B., Bakker, A.B. \& Salanova, M. (2006). The measurement of work engagement with a short questionnaire. Educational and Psychological Measurement, 66(4), 701-716. http://dx.doi.org/10.1177/0013164405282471

Scheier, M.F., \& Carver, C.S. (1985). Optimism, coping and health: Assessments and implications of generalized outcome expectancies. Health Psychology, 4, 219-247. $\mathrm{http}: / / \mathrm{dx}$.doi.org/10.1037/0278-6133.4.3.219

Snyder, C.R. (2000). Handbook of hope. San Diego, CA: Academic Press.
Solomon, T.S. (2012). Sex-role identity and work-family conflict in South African working mothers. Unpublished doctoral dissertation. Johannesburg, South Africa: Working mothers. Unpublished dof

Spence, J. (1993). Gender-related traits and gender ideology: Evidence for a multifactorial theory. Journal of Personality and Social Psychology, 64, 624-635. http://dx.doi.org/10.1037/0022-3514.64.4.624

Spence, J., Helmreich, R., \& Holahan, C. (1979). Negative and positive components of psychological masculinity and femininity and their relationships to self-reports of neurotic and acting out behaviors. Journal of Personality and Social Psychology, 37(10), 1673-1682. http://dx.doi.org/10.1037/0022-3514.37.10.1673

Spence, J. T., Helmreich, R. L, \& Stapp, J. (1975). Ratings of self and peers on sex role attributes and their relation to self-esteem and conceptions of masculinity and femininity. Journal of Personality and Social Psychology, 32, 29-39.

Stewart, M., Reid, G., \& Mangham, C. (1997). Fostering children's resilience. Journa of Paediatric Nursing, 12(1), 21-31. http://dx.doi.org/10.1016/S0882-5963(97) 80018-8

Strebel, A., Crawford, M., Shefer, T., Cloete, A., Dwadwe-Henda, N., Kaufman, M. et al., (2006). Social constructions of gender roles, gender-based violence and HIV/AIDS in two communities of the Western Cape, South Africa. Journal of Social Aspects of HIV/AIDS, 3(3), 516-528. http://dx.doi.org/10.1080/17290376.2006.9724879

Sugden, C. (2014). The relationship between sex role identity, perceptions of socia support and strength of network size. Honours dissertation. Johannesburg, South Africa: University of the Witwatersrand.

Thaler, K. (2011). Drivers of male perpetration of family and intimate partner violence in Cape Town. Centre for Social Science Research, working paper 289. Retrieved n.d., from http://www.cssr.uct.ac.za/sites/cssr.uct.ac.za/files/pubs/WP289_0.pdf

Wajsblat, L.L. (2011). Positive androgyny and wellbeing: A positive psychological perspective on gender role valence. Unpublished doctoral thesis. Hempstead, NY: Hofstra University.

Watson, D., Clark, L.A., \& Harkness, A.R. (1994). Structures of personality and their relevance to psychopathology. Journal of Abnormal Psychology, 103, 18-31. http://dx.doi.org/10.1037/0021-843X.103.1.18

Welle, B., \& Heilman, M.E. (2007). Formal and informal discrimination against women at work. In D. Steiner, S.W. Gilliland, \& D. Skarlicki (Eds.), Research in socia issues in management: Managing social and ethical issues in organization (pp. 229-252). Charlotte, NC: Information Age Publishers.

West, C., \& Zimmerman, D.H. (1987). Doing gender. Gender and Society, 1(2), 125-151. http://dx.doi.org/10.1177/0891243287001002002

Woodhill, B.M., \& Samuels, C.A. (2003). Positive and negative androgyny and their relationship with psychological health and wellbeing. Sex Roles, 48(11/12) 555-564. http://dx.doi.org/10.1023/A:1023531530272

Woodhill, B.M., \& Samuels, C.A. (2004). Desirable and undesirable androgyny: A prescription for the twenty-first century. Journal of Gender Studies, 13(1), 15-28. hrttp://dx.doi.org/10.1080/0958923032000184943

Wupperman, P., \& Neumann, C.S. (2006). Depressive symptoms as a function of sexroles, rumination and neuroticism. Personality and Individual Differences, 40, 189-201. http://dx.doi.org/10.1016/j.paid.2005.05.017

Youssef, C.M., \& Luthans, F. (2007). Positive organizational behavior in the workplace: The impact of hope, optimism and resilience. Journal of Management, 33(5), 774-800. http://dx.doi.org/10.1177/0149206307305562 